Puroila, A-M. (2019). Who am I? Shaping young children's identities through everyday narratives. In K.J. Kerry-Moran \& J-A. Aerila (Eds.), Story in children's lives: Contributions of the narrative mode to early childhood development, literacy, and learning (pp. 55-75). Springer.

\title{
Who Am I? Shaping Young Children's Identities Through Everyday Narratives
}

ANNA-MAIJA PUROILA

University of Oulu, Finland

anna-maija.puroila@oulu.fi

\begin{abstract}
Young children have largely been neglected in narrative identity research. This chapter is based on the premise that identity construction is a process that begins in the early years and is formed through the everyday narratives that comprise the daily interactions through which identities are constructed, negotiated, and performed. These everyday narratives provide children with the sense of who they are, who they will become, what kind of children they are expected to be, and the nature of the world in which they live. The chapter is based on research into everyday narratives produced in early education settings. I suggest that four themes frame the construction of children's narrative identities: the possession of material items; skills and competences; peer relationships; and the child's relation to the rules and conventions of the child care center.
\end{abstract}

Keywords: Identity construction; Everyday narratives; Narrative identity; Performativity 


\section{Introduction}

I am standing in the yard of a child care center, observing and listening to children. Children have dispersed into different play groups. A group of boys has developed a play theme around an imagined castle. Elli (a 3-year-old girl) wants to join in. Ville (a 5-year-old boy) says to Elli, "We can't play with you. You are too small!"

This episode draws attention to young children's interaction in an early education setting. Elli's desire is thwarted as she is excluded from the play because she is regarded as being too small. This brief glimpse into their interaction provides an example of how children's identities are shaped in relations between children and their social and cultural environments. By relating to and distinguishing themselves from each other, Elli and Ville make sense of themselves as individuals and social beings. While identifying Elli as a small child, Ville performs himself as belonging to the group of bigger children. In the cultural context of early education settings, belonging to the 'smalls' or 'bigs', the 'three-years-olds' or 'five-year-olds,' is significant for children's emerging identities (Ahn and Filipenko 2007; Konstantoni 2012; Olwig 2011; Puroila 2013). As Puroila and Estola (2014) note, being narrated as a member of the 'smalls' or 'bigs' implies values, social statuses, and power relationships that influence children's sense of self.

This chapter focuses on children's narrative identities in a child care center context. A growing body of research suggests that narratives are crucial for people's identities (McAdams 2011; Smith and Sparkes 2008). Young children, however, have largely been neglected in narrative identity research, generally due to the dominant conceptions of identity and narrative. The concept of identity usually refers to humans' responses to the question, "Who are you?" (Ahn 2011; Tracy and Robles 2013). Identity is often approached from the perspective of the individual's psychology as an essential and stable entity that they achieve in late adolescence or early adulthood (McAdams 2011; Smith and Sparkes 2008). From this perspective, young children are not interesting participants in identity research as they are working towards having identities. Narrative research, in turn, has traditionally emphasized the contents, form, and structure of verbally articulated accounts of adults' life events (Puroila 2013). Dimensions such as a linear progression of events, temporality, and a plot line consisting of a beginning, middle, and an end have been regarded as criteria for well-formed narratives (McAdams 2011). As young children have limited capacities to produce verbal narratives that fulfil these criteria, the space for exploring their narratives has been restricted (Puroila et al. 2012a; Puroila 2013).

This study is theoretically informed by a performative perspective on narrative identities (Puroila 2013; Smith and Sparkes 2008). Instead of approaching identity as an individual's coherent, internalized life story, the performative perspective highlights the social, relational, and dynamic dimensions of identity; the daily interactions through which individuals' multiple identities are negotiated and performed (Smith and Sparkes 2008). The performative perspective opens up new space for examining young children's identities from narrative viewpoints (Puroila 2013). With the aim of exploring young children's narrative identities, this study focuses on everyday narratives produced in an early education setting. An everyday narrative as a concept refers to daily interactions and practices through which children perform themselves and are performed by other interlocutors in a certain light (see Puroila 2013). The research questions include: How do children narrate themselves in a child care center context? How do they come to be narrated by other children and adults?

\section{Everyday narratives as sites for negotiating and performing children's identities}

Narrative researchers usually reject the assumption that identity is an essential, single entity, and instead view it in the plural and as connected to the situated and discursive practices 
through which identities are shaped (Ahn 2011; Smith and Sparkes 2008). Smith and Sparkes (2008), however, argue that "although there is a chorus of qualitative researchers singing that identities and selves are narratively constructed, they are not always in harmony" (p. 6). They present five distinct, though interrelated understandings of narrative identities: the psychosocial, the intersubjective, the storied resource, the dialogic, and the performative perspectives. Smith and Sparkes (2008) highlight that these perspectives should not be understood as mutually exclusive but rather as a continuum, with a 'thick individual' and 'thin social relational' focus at one end and a 'thin individual' and 'thick social relational' emphasis at the other (p. 7).

This study draws on the performative perspective on narrative identities that represents the 'thin individual' and 'thick social relational' emphasis in the afore-mentioned continuum (Smith and Sparkes 2008). Peterson and Langellier (2006) argue that the performative perspective has a significant function in re-situating the object of a narrative study: "Narrative is embodied in communication practices, constrained by situational and material conditions, embedded in and ordered by fields of discourse, and strategically distributed to reproduce and critique existing relations of power and knowledge" (p. 175). Employed in narrative identity research, the performative perspective requires focusing on the interactional and contextual aspects of narratives, rather than on narratives as cognitive, internalized structures through which individuals understand themselves. Accordingly, identities are understood as something that people do or perform, rather than have (Smith and Sparkes 2008).

In previous research literature, researchers use the concepts of a story and a narrative in many different ways. Whereas some researchers use the terms interchangeably, others view a narrative as a broader term than a story (Van Oers 2003; Hyvärinen 2008). I draw on conceptualizations in which two distinct though intertwining aspects of narration are distinguished; the content (What is told?) and the process (How and where the telling occurs?). While a story refers to the content, a narrative covers both the content and the process through which the story is produced. This chapter focuses on everyday narratives as sites for negotiating and performing young children's identities in an early education setting. I understand the concept of an everyday narrative as a dynamic meeting place where children's identities are shaped in relations between people and their environments (Ahn and Filipenko 2007; Puroila et al. 2012a). In accordance with previous studies, the 'performing' of children's identities includes not only spoken language but also other means of multi-modal narration, such as bodily activities, gestures, tone of voice, and emotional expressions (Puroila 2013; Smith and Sparkes 2008).

Moreover, I highlight the significance of the social, cultural, and material environment for the performing of children's identities. In previous research, the home environment, and especially mothers as primary caregivers, has been viewed as significant for young children's narrative identities (e.g., Reese et al. 2010). On the other hand, some studies acknowledge the importance of institutional education for children's identities, as contemporary generations of young children spend a large part of their childhood outside home in institutional early education settings (Farquhar 2012; Puroila 2013; Puroila and Estola 2014). As Farquhar (2012) maintains, such settings play a crucial role in young children's identity construction through the practices and technologies that provide social spaces for normality, regulation, and surveillance. Performing children's identities thus has close connections with moral development; what it is to be 'a good child'.

\section{Setting and participants}

\section{Study}

This study was conducted in a municipal child care center in an urban area in Northern Finland with a group of twenty-one children aged between three and six: eleven girls and ten boys. The staff consisted of three female educators: two kindergarten teachers and one trained nurse. The 
indoor spaces included two rooms, the corridor, and the toilet, and the group sometimes had the chance to use the center's common spaces, for instance the gym hall. The center was open from 6.30 a.m. until 5 p.m., and the children's daily activities were usually structured around regular routines.

In my previous studies, I have explored the daily lives of children in this group from diverse viewpoints, such as the nature of children's spontaneous narrating (Puroila et al. 2012a), children's narrated well-being (Puroila et al. 2012b), the child care center as a narrative environment (Puroila 2013), and the narrative identities of the youngest children (Puroila and Estola 2014). The focus of this chapter is the everyday narratives in which four children emerge as protagonists: Titta (a three-year-old girl); Nuutti (a five-year-old boy); Joni (a three-yearold boy); and Leevi (a five-year-old boy). The other children and educators are present in the narratives as interlocutors with Titta, Nuutti, Joni, and Leevi. As a researcher, I am also part of the everyday narratives because, as Spector-Mersel (2010) notes, narrative research is not neutral or clean from researchers' effects, as researchers influence by their mere presence.

\section{Co-composing everyday narratives}

The methodology of the study was based on ideas about narrative ethnography (Gubrium and Holstein 2008) and the multi-modality of children's narratives (Puroila 2013; see also Smith and Sparkes 2008). I spent a lot of time with the group of children during the course of oneand-a-half years, and I lived and co-composed the everyday narratives alongside the children and educators (see Clandinin et al. 2016). The notion of the multi-modality of children's narratives challenged traditional ideas about listening. Listening to children's multi-modal narratives demanded going beyond listening only with ears, and meant listening to the rich variation of languages, symbols, codes, and expressions through which children's identities were negotiated and performed (Puroila et al. 2012a). This kind of listening was not possible for an outsider observer, but rather required me to form relationships with the children and adults. As Caine et al. (2013) remark, narrative research involves a research orientation that grows out of being in relationships: "Through attending to the relational in-between space in narrative inquiry, possibilities arise to discover new ways of knowing and understanding" (p. 580).

The relational research orientation also challenges the research ethics. Hyry-Beihammer et al. (2012) argue that though important, it is not enough to obtain written consents and follow formal ethical protocols. Rather, researchers are responsible for treating participants in an ethical way throughout the research process. In my study, I had the consent of the children, their parents, the staff members, and the municipality. Moreover, I attempted to be sensitive and respect children and adults in different phases of the process. For instance, I joined the children's activities if invited, but avoided disturbing their playing situations if they did not want my participation. Similarly, I tried to adapt my role to suit adults' different situations. My role as a researcher thus varied on a situational basis.

Rather than organizing special occasions to generate research material, I observed children's daily situations, participated in their activities, and listened to their spontaneous narratives. I co-composed a vast collection of material with the children and educators through taperecording daily conversations and keeping written diaries. The research material was transcribed into a form of everyday narratives. In this study, I primarily use material generated at the end of my field work, which involved following one child during an entire day at the center. Thus, this chapter is based on everyday narratives drawn from Titta, Nuutti, Joni, and Leevi's day in the early education setting. 


\section{Interpreting and re-telling everyday narratives}

My approach to the everyday narratives was a holistic one, which influenced how I understood the entire research process and working with the narratives. In accordance with Spector-Mersel (2010), I view field work, co-composing the everyday narratives, interpretation, and writing as inseparable processes. From this perspective, the first interpretations were already made during the field work phase and when co-composing the narratives. Hence, the everyday narratives employed in this study do not reflect children's daily lives authentically, but rather are filtered through my interpretations and capacity to understand what is going on.

Lieblich (2014) suggests that the concept of narrative contradicts the idea of analysis; when analyzing narratives down to fractions there is a risk of losing the context expressed by the narratives. Rather than analyzing and fragmenting the everyday narratives into smaller units, my intention was to read and re-read the everyday narratives as a whole to interpret and better understand the children's narrative identities. Gradually, I began to perceive four different dimensions meaningful for children's narrative identities: the possession of material items; skills and competences; peer relationships; and the child's relation to the rules and conventions of the child care center.

Identifying these dimensions was not the end of the process; I continued the re-reading in parallel with previous research literature and aimed to place the everyday narratives and the previous research literature into a dialogue. Viljamaa (2012) calls this kind of approach dialogic re-reading and re-telling (pp. 20, 103). With dialogue, Viljamaa refers to knowledge that is accumulated in spaces between participants, between participants and researcher, and between research material and previous research literature. For the researcher, the dialogic rereading and re-telling means seeking to enter the spaces where knowledge and knowing stratifies into multiple layers in different narrative encounters. In this study, the dialogic rereading and re-telling involved constant movement; when writing this chapter, I moved back and forth between my memories of the field work, the research material on which this chapter is primarily based, what I have written about this group of children in my previous publications, and previous research literature. In what follows, I will re-tell the four dimensions of children's narrative identities by drawing examples from the everyday narratives and discussing them together with previous research literature. I will use the term 'everyday narrative' when referring to the whole research material, and the term 'example' when referring to the extracts from broader everyday narratives.

\section{Findings}

\section{I have: Performing children's identities through possession}

The everyday narratives provided insights into the meaning of material objects in shaping children's narrative identities. Children repeatedly told me and shared stories about getting new clothes, backpacks, movies, games, and books. Children discussed what they had, what they did not have, and what they wished to have. Thus, 'having' was present in the everyday narratives in many ways. In particular, the toys brought from homes to the child care center inspired the children and prompted them to narrate. During my field work, the children taught me much about the childhood consumer culture. I learned to know Bagugans, Spidermen, Zhu Zhu Pets, Disney princesses, Hero Factory figures, and numerous other trendy toys (see Puroila et al. 2012b; also Ruckenstein 2010; Wohlwend 2017). The following examples demonstrate how the dimension of having intertwined with children's narrative identities.

\section{Example 1.}

I learned to know Leevi as a child who is very interested in Hero Factory figures. One morning, Sami brought Hero Factory figures to the child care center. 
Sami: Leevi, look what I have with me!

Leevi takes one of the figures and begins to knock it down and put the pieces together. Sami and Leevi start to play with the figures; they fly the figures around the room.

Sami: Do you have this kind of figure?

Leevi: I've one that color, but it's a baddie.

Example 2.

After resting time, children come one by one to the room where I am sitting. Joni, Nuutti, and Pekka chat about Sami's Hero Factory figures. They seem to wait for Sami, but do not realize that Sami is on the other side of the room.

Joni: We (Sami and Joni) will play with Sami's Hero Factories. I'll ask Sami if I can have the one with a shredder.

Sami comes over with a bag filled with different Hero Factory figures.

Joni (smiling): Hey Sami, can I play with that one?

Sami gives each boy a figure. They begin to play.

Example 3.

Titta comes to me and shows three little princess figures she has brought from home.

AM: What are they?

Titta: Look, I've this Cinderella! I bought this with my mum from the market yesterday.

AM: Oh, it's new!

Titta nods. Alli joins our discussion, pointing at one of the figures.

Alli: I've got that, it's called Auroora.

AM: Auroora. And what are the names of these?

Titta: Cinderella and Bella and Sleeping Beauty.

AM: $M m$.

Alli to Titta: Can I play with that one? (pointing at one figure)

Titta ignores this question.

Titta: Veera and Niina and Hilla are not here yet.

The girls go to build with some blocks. Titta keeps the figures close to her.

In these examples, some children perform as owners of trendy toys. Even though many children explain that they have similar toys at home, the ownership is most concretely present in Sami and Titta, as they have brought their toys to the child care center. Similar to Nordtømme's (2012) study, the everyday narratives echo how material items create power relations and interplay with the children involved. In the first two examples, Sami utilizes his toys to connect other children to a joint play. This appears to be a successful strategy; in the first example Sami and Leevi - an older boy in the group - engage in a common play with Sami's Hero Factory figures. In the second example, Sami's figures connect a group of boys to a common play. In Example 3, Titta shares her joy at having new princess figures. In this situation, Alli shows interest in playing with Titta's figures, but Titta ignores Alli's suggestion; the girls begin to play together, but not with Titta's figures. These examples show that having a toy frames the children's right to choose the play and to include or exclude others. Similar to Sami's Hero Factory figures, Titta's princess figures cropped up in different situations throughout the everyday narratives.

In accordance with previous research, the everyday narratives reveal that material items are not neutral, but instead have an influence on children's relationships, opportunities for participation, and identities (Nordtømme 2012; Wohlwend 2017). Drawing on William James's conception of self, Hermans (2012) argues that the self is not restricted to inside a person, but rather extends to their environment:

$[\ldots]$ not only do one's thoughts and feelings $(\mathrm{Me})$ belong to the self but also that which the person calls his or her own (Mine) - like my body, my mother, my father, my children, and even my opponent - belongs to the self in a broader sense of the term. (p. 2) 
Besides extending the conception of identity to relations between humans, some studies have addressed how adults use material objects to express who they are and who they would like to be. The everyday narratives of this study propose that Dittmar's (2008) argument "to have is to be" has associations with young children's narrative identities. Having a material item makes a child a certain kind of child, thus producing statuses, hierarchies, and boundaries that are significant for the child's identities. For instance, during my field work I did not meet any boys who showed interest in princess figures, nor any girls who brought Hero Factory figures to the child care center. (I do not, however, argue that such boys and girls do not exist.) Having a nice toy was meaningful for how the child was treated by others; the other children admired their toys and sought their company in order to play with the toys.

The everyday narratives also drew attention to the space for children's own toys in the pedagogical culture of the child care center. As noted in previous studies, there are differences between educational institutions in terms of how children are allowed to bring their own toys (Puroila et al. 2012b; Ruckenstein 2010; Wohlwend 2017). In this group, the rules allowed the children to bring their own toys to the setting whenever they wanted. The educators showed interested and discussed the children's own toys but they did not restrict children's toy choices nor utilize the toys for pedagogical purposes (c.f., Wohlwend 2017). Therefore, the individually owned toys created an arena for children's peer culture and provided one dimension through which children were differentiated one from another.

\section{I can: Performing children's identities through competences}

When participating in children lives and re-reading the everyday narratives, I encountered several examples of children presenting themselves as competent. They did this by telling me about their new skills and proudly showing me their drawings and craft works, and they compared their accomplishments with their peers while drawing, playing, and working on assignments. They were also commended by the educators when they demonstrated their knowledge, skills, and progress in learning. Sometimes, the children seemed to search out praise from their peers and the educators - to be acknowledged as competent. These notions resonate with research literature highlighting the importance of positive experiences of achievements and competences for one's agency and well-being (e.g., Brown 2011; Kumpulainen et al. 2014). The following examples show how children performed as beingcompetent, being-less-competent, and being-not-competent in relationships with peers and between children and educators.

\section{Example 4.}

I am in a room where the educator has gathered all five-year-olds together for

'Viskari' (a club for five-year-olds). They discuss different shapes (circle, square, triangle). The educator challenges the children to think about how they could form a circle.

Leevi: I know! Let's make a ring.

The children hold hands and make a ring.

Educator: Excellent, Leevi!

\section{Example 5.}

Nuutti, Leevi, and Annika are playing together in the yard. They all shovel sand onto a swing. Nuutti takes the shovel from Leevi's hand.

Nuutti to Leevi: You should hold the shovel like this.

Nuutti gives the shovel back to Leevi. Leevi and Annika follow Nuutti's example.

Nuutti: It's good to swipe this way.

Other children follow his example.

Nuutti: Good work! 


\section{Example 6.}

Joni and Sami sit side-by-side eating breakfast. Sami is first finished.

Joni: Sami, can you wait for me?

Sami: Yeah.

Sami remains at the table.

Sami: Joni, I'll get the figures from my locker.

Sami goes to the locker room and comes back with a bag full of Hero Factory figures. Joni has now finished eating and takes his dishes to the trolley. Sami advises him where to put each of the dishes.

Joni: Yes, I know.

\section{Example 7.}

I am sitting at a table with Titta, Alli, and Veera who are coloring pictures. Titta has given one of her princess figures to each of the girls. I note that Titta colors very carefully, without crossing the border lines.

Veera: Look, Titta! (showing her picture)

Alli: Look, Titta! (showing her picture)

Titta glances at the pictures, then continues her own coloring.

Titta: They're quite messy.

These examples draw attention to different moments in which children's competences are performed. Example 4 occurred in an adult-directed situation with a clear pedagogical goal to support children's learning of shapes. In this example, Leevi had an opportunity to shine; he was the one who showed himself as a clever and skillful child, and the educator's reaction to Leevi's suggestion confirmed his success. Similar to Brown's (2011) study, this example shows the crucial role educators play in supporting children's perceptions of themselves as learners. In the everyday narratives, the children's competences were often performed in this kind of learning-oriented situations. This is not surprising, as the ideas of promoting children's development and increasing children's competences are inherent in institutional early education; indeed, one of the main purposes of early education is to promote children's growth, learning, and development. As Claxton and Carr (2004) argue, early education settings always have a learning curriculum, whether explicitly or implicitly articulated.

The other three examples above reveal the fleeting moments that provided space for children to demonstrate their competences. The performed competences did not only concern so-called academic skills; rather, the children expressed several kinds of skills, such as being able to play with sand, bring the dishes to the trolley, or color a picture. In Example 5, Nuutti played a leading role in the children's outdoor play. He treated the other children as if they were less competent by advising them in how to sweep the sand more effectively, and the other children maintained his leading role by following his suggestions. In Example 6, Sami showed his competence by giving advice to Joni about placing dishes on the trolley. However, Joni proved equally competent by rejecting the need for such advice. Finally, in Example 7, Alli and Veera seemingly searched for feedback from Titta, who did not appreciate the other girls' work. By dooming their colorings as 'messy,' and working carefully on her own picture, she portrayed herself as more competent than the other two.

In the everyday narratives, the children's competences provided one dimension for the children to differentiate themselves. Competences were thus significant for children's evolving narrative identities. However, competences did not emerge as measurable skills, inherent qualities, or unified properties of the child (see Ahn and Filipenko 2007; Smith and Sparkes 2008). Rather, competences appeared as narrated and performed aspects attached to particular children in particular situations. 


\title{
My friends: Shaping children's identities in the nexus of peer relations
}

The everyday narratives were full of episodes revolving around children's peer relations. On the one hand, there were narratives involving children who formed close friendships that endured over time. For instance, Joni and Sami often performed as best friends; they searched for each other's company and expressed loneliness when one was not present (see Examples 6 and 12). On the other hand, the everyday narratives also involved children who played with many peers and inhabited an extended nexus of social relationships. Negotiations about playmates penetrated the children's interactions throughout the everyday narratives. As the following examples show, 'who plays with whom' was a frequently addressed question among this group of children.

\author{
Example 8. \\ Pekka, Leevi, and Nuutti are building a castle with Lego blocks. \\ Pekka: Paavo won't play with us in the yard. \\ Nuutti: Who is he playing with? \\ Leevi: He'll be playing with Sami. We can play with many friends. \\ Pekka to Nuutti: You can't force me to play only with you! \\ Nuutti: No, I can't. \\ Pekka: I'll play with you another day.
}

\section{Example 9.}

I am standing in the yard and looking how a group of boys (Nuutti, Leevi, Paavo, and Pekka) are playing around a climbing frame. They begin to chat about who is allowed to join in.

Nuutti: We don't let girls come here.

Some of the boys: They're nasty!

The boys notice Annika (a girl) on the climbing frame.

The boys shout: Annika, you can't come here!

After a while, I note that the boys have included Annika in their play.

Nuutti: Let's go, boys!

\section{Example 10.}

Four girls are drawing and coloring pictures. Viivi finishes her drawing and begins to talk about who plays with whom.

Viivi: I know. Veera plays with Niina and Viivi with Hilla.

Titta: Someone must play with me.

Viivi does not pay attention to Titta. Titta gathers the papers and pens and takes her drawing to her locker. She takes her princess figures from the locker and goes to the window, glancing out.

Titta: When is my mom coming?

These examples were drawn from the 'free play' situations in which children could choose their playmates and activities (also Børve and Børve 2017; Konstantoni 2012; Wood 2014) and provide insights into children's preferences when choosing who to play with. One of the most striking dimensions in the everyday narratives was the children's tendency to develop common activities on a gendered basis, which is also obvious in the examples above. This is not surprising, as previous research literature presents notions about the significance of structural factors, such as gender, age, and ethnicity, in children's peer relations (Børve and Børve 2017; Konstantoni 2012; Puroila and Estola 2014; Wood 2014). The question also involves the process of identification, where similarities and differences form the basic dynamics through which identities are shaped. Applied to children's worlds, this means children must have 
something in common to form relationships and identify themselves as members of certain social groupings (Konstantoni 2012).

In Example 8, a group of boys negotiated the principles by which playmates were chosen. It was clear from the entire research material that Nuutti enjoyed a high status in the group, and other children, both boys and girls, often searched out his company and acceptance. Nuutti also played a leading role in several daily situations (see Examples 5 and 9). The hierarchies of the group colored the boys' conversation in Example 8. Unlike in many other situations, Nuutti found himself on the losing side; he had to admit that he could not always decide who plays with whom. In Example 9, outdoor play initially involved the group of boys, who performed their male identity by inventing rules that girls were not allowed to join. However, Annika entering their territory changed the situation. Although they first forbade her from playing, she was soon regarded one of 'the boys'. Example 10 provides a view of peer relations among the youngest girls in the group. Although Titta expressed her willingness to be included in the joint play, she was left alone; she did not stand up to take her place in the other girls' play. Her actions implied loneliness and being left alone made Titta miss her mother.

These examples draw attention to the dynamics through which peer relations shape children's identities. Although some social bonds and power structures transcend situations, such as close friendships and social hierarchies, they do not seem absolute or unchanging in the context of this study. For instance, Nuutti's high status in the group was questioned when the other children resisted him and made their own choices. The narratives also echo how flexibly children re-created the boundaries between the playing groups. The group of boys accepted Annika to play a role of 'a boy', while Titta was excluded from the play despite having the attractive princesses. Similar to previous studies, the everyday narratives portray peer relations as an arena for the politics of belonging, where boundaries between 'us' and 'them' are created, maintained, and contested (Sumsion and Wong 2011; see also Over 2016). Through this boundary maintenance, children were identified as insiders and outsiders in relation to the groupings. As Konstantoni (2012) argues, being included and chosen as a friend forms an important aspect of children's lives, their development and well-being.

\section{My place: Children's identities shaped by cultural rules and conventions of the child care center}

The everyday narratives provided a range of diverse insights into the pedagogical and institutional cultures of the child care center, which are important for shaping children's identities. As Tuval-Mashiach (2014) notes, all single narratives echo the culture and shared meaning systems in which narratives are created and performed. An increasing body of research maintains that the pedagogical and institutional cultures of early education settings shape children's identities through framing and regulating the social spaces of normality (Edmiston 2010; Farquhar 2012; Olwig 2011; Puroila and Estola 2014). Children's identities thus have a close connection with a moral perspective: What are good and desirable children like in the context of early education settings?

In accordance with previous studies, the child care center appeared as a well-structured place where physical spaces, material items, and people's actions were framed by a particular spatio-temporal order (Olwig 2011; Puroila 2013). On the one hand, cultural conventions were expressed explicitly; for instance, the daily schedule was made visible using a series of pictures representing the order of daily routines and activities (see Puroila et al. 2012b). In the yard, the fences indicated a clear border that children were not allowed to cross without the educators' company, while the borders between the different groups' indoor spaces were marked with doors and walls. The children's lockers and chairs were labeled with nametags; "this is my place" and "this is my locker" were often heard during the children's daily activities. On the other hand, some cultural rules were less explicit, and these became particularly evident when children did not behave as expected and when they contested or broke the rules. In the extracts 
above, the moral landscape of children's lives is mapped by rules concerning how to use the physical spaces and material items, how to engage in the tasks assigned, how to treat other children, and how to behave in different situations. The examples below offer insights into how the children navigated in the culturally marked landscape of their center.

Example 11.

I am sitting on a bench in the locker room in which children are playing. Two cleaners go through the locker room to a small room meant for their detergent and cleaning implements. Sami shuts the door behind the cleaners and runs away laughing. Leevi remains beside the door. The educator enters the locker room and reminds Leevi that children are not allowed to enter the cleaners' room. Leevi moves from the door, giggling.

Leevi (to Sami): The cleaners are locked in the room forever!

Example 12.

The educator has organized material on a table for children to make cards, as Fathers' Day is coming. The educator asks children to engage in card making in small groups. Joni has not yet made his card, as he and Sami have played the morning with Sami's Hero Factory figures.

Educator: Hey, Joni, please come here to make the card!

Joni: I'd like to get this [Hero Factory figure] ready.

Educator: Does it take a long time?

Joni: No (continuing his play).

Educator: Joni, please, come!

Joni leaves the figure and comes to the table. He makes the card and wraps it with the educator's help.

Educator: Thank you, Joni!

Joni runs back to Sami.

Joni: I got off now, doesn't it take a long time?

Example 13.

I am observing children who are playing in the yard. Leevi runs to one boy (Heikki), shoves him down, and presses him on the back.

Leevi: Nuutti, come here!

Heikki begins to cry. An educator approaches the boys.

Educator: What's going on? Why's Heikki crying?

Heikki: Leevi's teasing me.

Educator (to Leevi): Why?

Leevi: They bullied us.

The educator talks to Leevi about how he should behave.

Example 14.

The children are gathered in a locker room for a circle-time situation. They sit on benches and wait for an adult. Nuutti is sitting between two boys. An educator enters the room.

Educator: Nuutti, do you have such a place that you can sit there?

Nuutti: Yes.

The examples above took place either in the rooms dedicated for this group or in the yard, spaces that formed the 'stages' where children's identities were performed (see Puroila 2013; also Børve and Børve 2017). Example 11 involves the spatial regulations of the center; the border between the permissible and prohibited spaces for children lies between the locker room and the cleaners' room. Even though Leevi did not cross this border, he was reminded that the children are not allowed to enter the cleaners' room. Example 12 offers a glimpse of the curricular activities of this group; in the light of the everyday narratives, it was obvious that 
the children had plenty of space to choose their activities, which reflects the idea of a playbased curriculum (see Wood 2014). As Joni's case in Example 12 reveals, the educator respected the children's engagement with play, and therefore the children could complete the task of making cards within a flexible time frame. However, one can see that the educator was determined that Joni must make the card. Even though Joni's mind seemed set on the Hero Factory figures, he met the educators' expectations by making the card.

In addition to Examples 11 and 12, there were a number of other situations where children adapted themselves to the moral order of the center, thus performing as nice and obedient children. However, there were clear differences between the children in this respect. Titta often played the role of 'a good girl'; she managed the conventions and rules of the center very well and took care that other children did not break the rules. Joni usually adapted to the center rules as well, and rarely contested them. Of the four children considered in this chapter, it was more difficult for Nuutti and Leevi to fulfil the adults' expectations. In many situations, these boys were on a collision course with the moral order of the center; they appeared too energetic and too noisy to play the role of a desirable child. These boys often found themselves in conflict with other children in the group, like Leevi in Example 13. As noted in previous research, misbehavior may have a cumulative nature in terms of children's emerging identities; the more children perform as trouble-makers, the more the community begins to expect this kind of behavior from them (Puroila 2013). According to my interpretation, the educator views Nuutti as a potential trouble-maker in Example 14. She is seemingly concerned whether Nuutti is able to sit quietly when seated between two boys. Seating is one of the various means by which educators maintain order among children and indicate a child's place within the group (Puroila 2002).

\section{Discussion}

The questions "Who am I?" and "What constitutes the world in which I live?" are among the most fundamental ones that children encounter already in their early years. In many Western societies, a growing number of children spend many of their waking hours in institutional early education settings. These settings provide young children with a significant context for their development; a context where they can make sense of themselves and the surrounding world. On the one hand, it is the first context that allows young children to mirror themselves against their peers and learn to participate in the creation of peer culture (Børve and Børve 2017; Konstantoni 2012). On the other hand, it is a context for children's civilizing process in which public educational policies frame children's shaping as social beings (Farquhar 2012; Olwig 2011). The present study offers insights into how children's narrative identities are negotiated and performed between children and the complex nexus of social, material, and cultural relationships. The study both contributes to early childhood education research and has implications for educational practices.

\section{The potential and challenges of the narrative approach in research with young children}

Previous research has proved the potential of narrative approaches in research with young children. Exploring young children's lives from narrative viewpoints has provided insights into, for instance, children's psychological and linguistic development (e.g., Engel 2006; Nicolopoulou 2008). However, research on young children's narrative identities has been scarce. This is due to the long tradition of narrative research that has placed the emphasis on individual narrators' verbal stories of their past life events. During the past decade, there has been increasing interest in expanding narrative research beyond the mere verbally articulated narratives towards scrutinizing narratives as social practices in context (Lannamann and 
McNamee 2011; Striano 2012). Research on narrative identities has also become more complex and multi-voiced; research literature contains "various ideas of what narrative identities and selves are and how they should be studied" (Smith and Sparkes 2008, p. 6). This expansion of narrative research broadens the opportunities for utilizing narrative approaches in research with young children (Puroila 2013).

This study contributes to early childhood education research by opening new spaces for applying narrative approaches in studies of young children's identities. Rather than restricting the concept of narrative to children's verbal accounts, this study conceptualized narratives as dynamic meeting places where children's identities are shaped in relations between people and their environments (see Ahn and Filipenko 2007). The everyday narratives explored indicated the holistic nature of children narrating, as children's verbal accounts were connected closely to their bodily actions, emotional expressions, gestures, and the situation where narrating occurred. Building and knocking down Hero Factory figures, sweeping sand, playing, drawing, crying, climbing, and participating in the daily routines of the setting had a crucial function in the narratives. By looking merely at the children's verbal accounts, the narratives would not be understandable.

The performative perspective applied in this study offered a fruitful framework for exploring young children's narrative identities. This perspective challenged me to focus on how narrative identities were negotiated and performed in the dynamic, relational space between children and their contexts. As a researcher, I was essentially part of the nexus of relations under study. Clandinin et al. (2016) maintain that as narrative inquirers we do not try to get out of stories; rather, "we linger in the complex layers of the intertwined and interwoven stories" (p. 20). The everyday narratives co-composed in this study provided a rich and lifetasting ground for this 'lingering,' that is, going back and forth between various narratives, my memories from the field work, and previous research literature.

Its highly relational nature can be seen as both a strength and a limitation of this study. On the one hand, the study shows that engaging in living, telling, re-living, and re-telling the everyday narratives enabled getting close to the children's daily lives. Close reading and rereading of small, even minimal, extracts of daily interactions provided insights into the children's life events in their complexities. Regardless of my honest willingness to understand children's lives, I cannot escape the fact that my interpretation and understanding are restricted unavoidably by my role as an adult researcher, nor can I argue that the findings of this study are generalizable. However, the study may provide inspiration for further studies and provoke memories, images, and feelings of familiarity in the readers beyond the research context.

\section{Young children's identities: A crucial part of their daily lives}

Early childhood education research and practice has long been dominated by age-dependent and individually focused developmental theories that have provided an overarching framework for understanding early years (Edmiston 2010; Hedges and Cullen 2012; Urban 2012). From the developmental viewpoint, the interest in young children's identities is focused primarily on their 'becoming', that is, the developmental steps through which children build their identities. As Edmiston (2010) remarks, the developmental theories drawn from the ideas of Piaget or Kohlberg tend to assume that children are at less competent stages of their cognitive and moral development than adults: "Young children are inherently more egocentric, lacking in deep empathy, and less able than adults to abstractly and rationally reason about moral issues" (p. 198).

This study explored young children's identities from a slightly different perspective thus providing an alternative and complementary theoretical view for understanding children's identities. In accordance with a growing body of research literature, this study highlights identity as a dynamic and relational phenomenon that is crucial to young children's daily lives in early education settings (e.g., Ahn 2011; Farquhar 2012; Konstantoni 2012). The study offers 
glimpses of a variety of daily interactions in which children relate their selves to other children and adults, and to the material, institutional and pedagogical cultures of the early education setting. The findings reveal that four intertwining dimensions permeate the negotiating and performing of children's identities in the context of this study: the possession of material items; skills and competences; peer relationships; and the child's relation to the rules and conventions of the child care center. These findings indicate that children's identities are interwoven tightly into the whole texture of the early education setting.

In addition, the findings of the study draw attention to three aspects relevant to educational practices in early education settings. First, children appeared both as active and passive in negotiating and performing their identities. They not only performed identities themselves but also became narrated and treated in a particular way by other interlocutors. From this perspective, the quality of interaction among children and between children and educators forms an important means of influencing children's identities. Second, the shaping of children's identities emerged as both situation-specific and trans-situational by nature. Even though the children's identities often changed from situation to situation, some aspects of identities seemed to cumulate and offer continuity in the children's lives. For instance, close friendships and the role of a trouble-maker characterized a variety of some children's situations. Undoubtedly, all children sometimes encounter unpleasant matters in the heat of everyday life, such as negative feedback and disputes. However, being repeatedly excluded, rejected, or labelled as a trouble-maker is a real threat to the child's well-being and development. Therefore, educators need to be sensitive to the relationships and interactional patterns that exist in the setting. Third, the children's identities were shaped by both adapting to and contesting and transgressing the power structures of the child care center. The children's identities were connected closely to how they exercised their agency within the hierarchies of the peer group and the social and moral order of the setting. This notion calls for reflecting on the moral basis of early childhood education: What are the desirable children like in institutional early education settings? What kinds of identities are preferred and promoted? The Table 1. summarizes some practical tips for educators how to utilize everyday narratives in supporting the development of children's positive identities in early education settings.

Table 1. Practical tips for utilizing everyday narratives in early education settings

Provide space for
children's
spontaneous and
multimodal
narratives

Engage in children's narratives
- Appreciate children's spontaneous initiatives to narrate and share their experiences.

- Create opportunities for children to narrate in multiple ways: in addition to verbal narratives children tell, for instance, by singing, drawing, playing, and moving.

- Pay attention to different children's ways of narrating; those who tend to remain silent have also their stories to be shared.

- Organize time and space for yourself to engage in children's narratives: utilize the potential involved in diverse daily moments and encounters.

- Create fruitful situations for narrating and listening: keep close to children and encounter children face-to-face.

- Recognize adults' tendency to speak a lot; reduce your own speech and 


\section{Utilize the potential of everyday narratives in developing the pedagogical practices of the setting}

show your interest in what children are expressing.

- Exercise your skills of listening to children's multimodal narratives: listening requires using not only ears but all senses.

- Document everyday narratives cocreated in the setting; observe, write diaries, and use technologies

- Provide spaces for educators to share and reflect on everyday narratives.

- Reconsider the significance of materiality for children's identities; reflect on practices connected with physical spaces and material items.

- Reflect on your interactional patterns; reconsider how you support children's positive sense of self, give positive feedback, and strengthen children's sense of being competent.

- Reflect on how you support children's peer interaction and peer culture: help children form relationships; support children's sense of belonging; create practices of intervening in exclusion and bullying.

- Reflect on the moral basis of early childhood education in the setting; reconsider explicit and hidden rules that frame children's moral development.

\section{Conclusion}

This study portrays a child care center as a context in which young children engage in a variety of relations with their social, material, and cultural environment. These relations constitute the messy landscape where children's narrative identities are continuously negotiated and performed. Throughout their daily lives, children narrate about themselves and they encounter narratives about who they are, who they will become, and what kind of children they are expected to be. These narratives are important, as they provide children with a view of how they relate to other people and the world in which they live. The findings of this study challenge us to reconsider the significance of daily interactions, material and social environments, educational practices, and institutional and pedagogical cultures in terms of children's narrative identities. In light of the findings, we can see that the function of institutional early education goes far beyond promoting children's academic learning. Rather, the development of children's personalities is on view in a holistic manner throughout the day in a range of situations in such settings. 


\section{References}

Ahn, J. (2011). Review of children's identity construction via narratives. Creative Education, 2(5), 415-417.

Ahn, J. \& Filipenko, M. (2007). Narrative, imaginary play, art, and self: Intersecting worlds. Early Childhood Education Journal, 34(4), 279-289.

Børve, H.E. \& Børve, E. (2017). Rooms with gender: Physical environment and play culture in kindergarten. Early Child Development and Care, 187(5-6), 1069-1081.

Brown, S. (2011). Looking across curricular structures. Early Childhood Education Journal, 39(4), 257-265.

Caine, V., Estefan, A., \& Clandinin, D.J. (2013). A return to methodological commitment: Reflections on narrative inquiry. Scandinavian Journal of Educational Research, 57(6), 574-586.

Clandinin, D.J., Caine, V., Lessard, S. \& Huber, J. (2016). Engaging in narrative inquiries with children and youth. New York and London: Routledge.

Claxton, G. \& Carr, M. (2004). A framework for teaching learning: The dynamics of disposition. Early Years, 24(1), 87-97.

Dittmar, H. (2008). To have is to be? Psychological functions of material possession. In H. Dittmar (Ed.), Consumer culture, identity and well-being. The search for the 'good life' and the 'body perfect' (pp. 25-48). Hove: Psychology Press.

Edmiston, B. (2010). Playing with children, answering with our lives: A Bakhtinian approach to coauthoring ethical identities in early childhood. British Journal of Educational Studies, $58(2), 197-211$.

Engel, S. (2006). Narrative analysis of children's experience. In S. Greene \& D. Hogan (Eds.), Researching children's experience. Approaches and methods (s. 199-216). London: Sage.

Farquhar, S. (2012). Narrative identity and early childhood education. Educational Philosophy and Theory, 44(3), 289-301.

Gubrium, J.F. \& Holstein, J.A. (2008). Narrative ethnography. In S.N. Hesse-Biber \& P. Leavy (Eds.), Handbook of emergent methods (pp. 241-264). New York: The Guilford Press.

Hedges, H. \& Cullen, J. (2012). Participatory learning theories: A framework for early childhood pedagogy. Early Child Development and Care, 182(7), 921-940.

Hermans, H.J.M. (2012). Dialogical self theory and the increasing multiplicity of I-positions in a globalizing society: An introduction. In H.J.M. Hermans (Ed.), Applications of dialogical self theory. New directions for child and adolescent development, number 137 (pp. 1-21). San Fransisco: Jossey-Bass. 
Hyry-Beihammer, E-K., Estola, E., \& Syrjälä, L. (2012). Issues of responsibility when conducting research in a northern rural school. International Journal of Qualitative Studies in Education, 26(8), 1062-1078.

Hyvärinen, M. (2008). Narrative form and narrative content. In I. Järventie \& M. Lähde (Eds.), Methodological challenges in childhood and family research (pp. 43-63). Tampere: Tampere University Press.

Konstantoni, K. (2012). Children's peer relationships and social identities: Exploring cases of young children's agency and complex interdependencies from the Minority World. Children's Geographies, 10(3), 337-346.

Kumpulainen, K., Lipponen, L., Hilppö, J. \& Mikkola, A. (2014). Building on the positive in children's lives: A co-participatory study on the social construction of children's sense of agency, Early Child Development and Care, 184(2), 211-229.

Lannamann, J.W. \& McNamee, S. (2011). Narratives of the interactive moment. Narrative Inquiry, 21(2), 382-390.

Lieblich, A. (2014). About Amos: Reading with our heart. Special issue: Multiplicity and commonality in narrative interpretation. Narrative Works: Issues, Investigations, \& Interventions 4(1), 114-124.

McAdams, D. (2011). Narrative identity. In S.J. Schwartz, K. Luyckx, \& V.L. Vignoles (Eds.), Handbook of identity theory and research (pp. 99-115). New York: Springer.

Nicolopoulou, A. (2008). The elementary forms of narrative coherence in young children's storytelling. Narrative Inquiry, 18(2), 299-325.

Nordtømme, S. (2012). Place, space and materiality for pedagogy in a kindergarten. Education Inquiry, 3(3), 317-333.

Olwig, K.F. (2011). Children's sociality. The civilizing project in the Danish kindergarten. Social Analysis, 55(2), 121-141.

Over H. (2016). The origins of belonging: Social motivation in infants and young children. Philosophical Transactions. R. Soc. B 20150072. http://dx.doi.org/10.1098/rstb.2015.0072

Peterson. E.E. \& Langellier, K.M. (2006). The performance turn in narrative studies. Narrative Inquiry, 16(1), 173-180.

Puroila, A-M. (2013). Young children on the stages: Small stories performed in day care centers. Narrative Inquiry, 23(2), 323-343.

Puroila, A-M. (2002). The multiple faces of everyday life: Frame analysis of early childhood practices. European Early Childhood Education Research Journal, 10(2), 31-47.

Puroila, A-M. \& Estola, E. (2014). Not babies anymore: Young children's narrative identities in Finnish day care centres. International Journal of Early Childhood, 46(2), 187-203. 
Puroila, A-M., Estola, E. \& Syrjälä, L. (2012a) Does Santa exist? Children's everyday narratives as dynamic meeting places in a day care centre context. Early Child Development and Care, 182(2), 191-206.

Puroila, A-M., Estola, E. and Syrjälä, L. (2012b). Having, loving, and being: Children's narrated well-being in Finnish day care centres. Special issue: Early Child Care and Education in Finland. Early Child Development and Care, 182(3-4), 345-362.

Reese, E., Chen, Y., Jack, F., \& Hayne, H. (2010). Emerging identities: Narrative and self from early childhood to early adolescence. In K.C. McLean \& M. Pasupathi (Eds.), Narrative development in adolescence (pp. 23-43). New York: Springer.

Ruckenstein, M. (2010) Time scales of consumption: Children, money and transactional orders. Journal of Consumer Culture, 10(3), 383-404.

Smith, B. \& Sparkes, A.C. (2008). Contrasting perspectives on narrating selves and identities: An invitation to dialogue. Qualitative Research, 8(1), 5-35.

Spector-Mersel, G. (2010). Narrative research. Time for a paradigm. Narrative Inquiry, 20(1), 204-224.

Striano, M. (2012). Reconstructing narrative. A new paradigm for narrative research and practice. Narrative Inquiry, 22(1), 147-154.

Sumsion, J., \& Wong, S. (2011). Interrogating 'belonging' in belonging, being, and becoming: The Early Years learning framework for Australia. Contemporary Issues in Early Childhood, 12(1), 28-45.

Tracy, K. \& Robles, J.S. (2013). Everyday talk: Building and reflecting identities. New York: The Guilford Press.

Tuval-Mashiach, R. (2014). Life stories in context: Using the three-sphere context model to analyze Amos's narrative. Special issue: Multiplicity and commonality in narrative interpretation. Narrative Works: Issues, Investigations, \& Interventions 4(1), 125-145.

Urban, M. (2012). Researching early childhood policy and practice. A critical ecology. European Journal of Education, 47(4), 494-507.

Van Oers, B. (2003). Multiple narratives of childhood: Tools for the improvement of early childhood education. In B. van Oers (Ed.), Narratives of childhood: Theoretical and practical explorations for the innovation of early childhood education (pp. 9-26). Amsterdam: VU University Press.

Viljamaa, E. (2012). Lasten tiedon äärellä. Äidin ja lasten kerronnallisia kohtaamisia kotona. [With children's knowledge. Narrative encounters of a mother and children at home.] Oulu: University of Oulu.

Wohlwend, K.E. (2017). Who gets to play? Access, popular media and participatory literacies. Early Years, 37(1), 62-76.

Wood, E.A. (2014). Free choice and free play in early childhood education: Troubling the discourse. International Journal of Early Years Education, 22(1), 4-18. 